\title{
A ATENÇÃO E O CAMINHAR NA FORMAÇÃO FILOSÓFICA OU A EXPERIÊNCIA COMO EXPOSIÇÃO E VULNERABILIDADE
}

\author{
Genivaldo de Souza Santos ${ }^{1,2}$, Rodrigo Pelloso Gelamo ${ }^{1,3}$ \\ Universidade Estadual Paulista Júlio Mesquita Filho - FFC - UNESP ${ }^{1}$, Pós-doutorando em Filosofia da Educação ${ }^{2}$, \\ Programa de Pós-graduação em Educação ${ }^{3}$, Marília, SP, E-mail: genivaldo@ifsp.edu.br, gelamo@gmail.com.
}

\begin{abstract}
RESUMO
O presente trabalho traz resultado de nossa pesquisa (em desenvolvimento) relativo ao estágio pósdoutoral no qual investigamos os sentidos, limites e possibilidade da atenção na formação filosófica e suas repercussões no ensino de filosofia e em práticas de ensino filosóficas, face aos desafios colocados pela escola contemporânea. A partir de uma perspectiva teórica que aborda a experiência do pensamento como experiência do caminhar, sintetizamos nosso problema de pesquisa nos seguintes termos: Quais as relações entre atenção e a experiência do caminhar, bem como, quais seus limites e possibilidades para uma formação filosófica? Objetivamos relacionar atenção e a experiência do caminhar, visando o adensamento da reflexão acerca da formação filosófica. Metodologicamente utilizamos a abordagem qualitativa, com pesquisa bibliográfica. Os resultados parciais indicam uma relação problemática da atenção e do caminhar na constituição do sujeito do conhecimento, de corte moderno e representacional, pois ambos exigem um outro sujeito, o da experiência.
\end{abstract}

Palavras-chave: Atenção; caminhar; formação filosófica; ensino de filosofia.

\section{ATTENTION AND WALKING IN PHILOSOPHICAL FORMATION OR EXPERIENCE AS EXPOSURE AND VULNERABILITY}

\begin{abstract}
The present work is the result of our research (in development) related to the postdoctoral stage in which we investigate the senses, limits and possibility of attention in the philosophical formation and its repercussions in the teaching of philosophy and in philosophical teaching practices, given the challenges posed By the contemporary school. From a theoretical perspective that approaches the experience of thought as an experience of walking, we synthesize our research problem in the following terms: What are the relationships between attention and the experience of walking, and what are their limits and possibilities in philosophical formation? We aim to analyze the relationship between attention and the experience of walking, aiming at the reflection on philosophical formation. Methodologically we use the qualitative approach, with bibliographical research. Partial results indicate a problematic relation of attention and movement in the constitution of the modern and representational subject of knowledge, since both require another subject, that of experience.
\end{abstract}

Keywords: Attention; walk; Philosophical formation; Teaching philosophy. 


\section{INTRODUÇÃO}

O presente trabalho traz resultados parciais do desenvolvimento do projeto de Pósdoutoramento intitulado Limites e possibilidade da atenção na formação humana, vinculado ao Programa de Pós-graduação em Educação da UNESP - Campus Marília, cujo objetivo geral visa compreender os sentidos, limites e possibilidades da atenção nos processos de formação humana e suas implicações para o ensino de filosofia em particular. Tomamos como objeto de pesquisa o fenômeno da atenção dimensionado em seu aspecto ético, em que sujeito e objeto permanecem abertos à transformação (MASSCHELEIN, 2008).

O tema da atenção recebeu um tratamento filosófico através de autores que transitam nos campos da filosofia e da filosofia da educação contemporâneas (ESQUIROL, 2008; MASSCHELEIN, 2008, HADOT, 1999, 2003, 2009; BOSI, 2003), assumido neste trabalho como um estado geral em que o sujeito mantém-se aberto e alerta aos objetos e situações aos quais está vinculado, permitindo que eles possam se apresentar e não apenas serem representados pelo pensamento, muito embora este mesmo sujeito mantenha o foco de sua atenção voltado para o objeto ou a situação nos quais está envolvido. Um processo em que o sujeito do conhecimento cartesiano cede lugar ao sujeito da experiência (MASSCHELEIN, 2008). Em suma, trata-se da manutenção de um estado especial (e ao mesmo tempo prosaico) que se produz como uma interrupção da constituição do próprio sujeito do conhecimento (moderno e representacional) ${ }^{1}$.

Nossa experiência docente e nossa pesquisa acadêmica tem mostrado que uma experiência de pensamento é necessária para a formação (aprendizagem) filosófica, que pode se revelar como uma caminhada, cujo início não comporta garantias, nem de chegada, nem da certeza de que se trata do melhor caminho a ser trilhado.

Esta concepção de formação filosófica contrasta com aquela associada à transmissão/assimilação de certas tradições presentes na história da filosofia, com percursos predefinidos e com os riscos minimizados. Porém como descreve Benjamim (2013), sobrevoar a floresta é diferente de percorrer seus caminhos a pé, devido à força exercida pela estrada que comanda a caminhante.

Henry David Thoreau (2012), Frédéric Gros (2014) e David Le Breton (2015), assumem a experiência do caminhar em um registro formativo-filosófico diferente do sentido performático atribuído ao termo usualmente. A partir do sentido atribuído por eles formulamos o problema que animará a presente investigação nos seguintes termos: Quais as relações entre atenção e a experiência do caminhar, bem como seus limites e possibilidades na formação filosófica?

\section{METODOLOGIA}

Do ponto de vista metodológico, por sua natureza eminentemente teórica, a investigação foi pautada pela abordagem qualitativa, com pesquisa bibliográfica. Por tratar-se de uma pesquisa

\footnotetext{
${ }^{1}$ Em relação a expressão moderno/representacional destacamos o cogito cartesiano, que comporta uma ruptura substancial entre a res cogitans e a res extensa, isto é, a ruptura entre a - coisa pensante (consciência, notadamente negativa, não-mensurável, não-tangível, não-extensiva) e a coisa extensa (o mundo/objetos, que podem ser mensurados, pesados, comparados, são espaciais e extensivos, com propriedades sensíveis), inaugurando uma concepção dualista e irreconciliável da realidade, ao separar substancialmente, a realidade espiritual da material, cuja diferença entre as duas substâncias diz respeito à sua natureza. Esta separação metafísica repercutiu não apenas na epistemologia, instaurando a relação dual e essencial entre sujeito-objeto, entre o ser que pensa e o ser- pensado, porém introduziu-se também em outras áreas, atingindo o cerne mesmo das instituições do ocidente cristão. De acordo com Leopoldo e Silva (2001), interpretando Descartes, a hegemonia do sujeito corresponde ao que se convencionou denominar de primado da representação, compreendido como todo e qualquer conteúdo presente na mente. A palavra representação, de raíz medieval, conota para Abbagnano $(2003$, p. 853) a referência a uma imagem ou ideia, ou ambas as coisas. Seu uso foi sugerido pelos escolásticos através do conceito de conhecimento como "semelhança" do objeto. Posteriormente, Imannuel Kant estabelece uma noção geral de representação, considerando-a gênero de todos os atos ou manifestações cognitivas, independentemente de sua natureza de quadro ou semelhança, sendo que desse modo passou a ser usado na filosofia. Em outras palavras, a representação pode ser concebida como mediação necessária para qualquer ato cognitivo, bem como um limite para a compreensão ocidental de um conjunto de fenômenos que se implicam ou em termos deleuzianos que se complicam, tais como conhecimento, ensino, aprendizagem. Tendo em vista que o sujeito moderno concebido como substância pensante, não consegue atingir seu objeto/mundo diretamente, pois este, coisa extensa, difere-se substancialmente do sujeito.Neste sentido, a representação coloca-se como substituto, como representante do objeto na relação epistemológica entre o sujeito e o mundo/objeto. Por ser produzido pelo sujeito, em última instância a relação epistemológica poderia significar uma relação em que o sujeito epistemológico configura a si mesmo a medida em que configura seu o objeto por meio da intencionalidade.
} 
com forte aspecto teórico, nossa metodologia apoia-se, sobretudo, na análise bibliográfica. O material bibliográfico de referência foi buscado no campo da filosofia, especialmente contemporânea, mas também nos campos das ciências da educação.

Devido a esta escolha metodológica, é preciso considerar que todo o trabalho de exame, análise e síntese do pensamento supõe um aprofundamento nos diferentes discursos com o objetivo de abranger os seus significados e se aproximar dos sentidos ali afirmados. A partir da pesquisa bibliográfica, empreende-se o trabalho de natureza conceitual, tomando-se a educação como campo problemático que instiga a buscar enfrentamentos de natureza teórica e prática.

\section{RESULTADOS}

Para o filósofo catalão Josep Maria Esquirol (2008), existem dois modos diametralmente opostos de "ver o mundo": o que se baseia no olhar tecnocientífico e o que é sustentado pelo olhar atento, sendo este condição para a constituição de um olhar ético. Para ele, o olhar atento tem como núcleo íntimo o fenômeno da atenção, associado às ideias de estar "acordado", "desperto", "lúcido", contrário aos estados de desatenção, mais próximos ao delírio, à suposição e à sonolência.

O autor também descreve a atenção como um movimento, uma atividade (prestar ou colocar atenção; focalizar; selecionar) e como um estado (estar atento, estar vigilante), contrastando com outros estados: distraído, ensimesmado, sonolento, entre outros. A atenção teria o potencial de apurar os sentidos e de ampliar a vulnerabilidade do sujeito em relação aos objetos/situações que requerem atenção, dinamizando uma atitude que solicita um esforço e uma pausa para sair do fluxo que mostra um mundo "liso", uniforme e homogêneo.

Neste sentido, trata-se de uma atenção associada, desde o início, com o tema do Respeito, em conformidade a suas raízes etimológicas, que indicaria o estabelecimento de uma distância apropriada entre o sujeito e seu objeto/situação.

Em suma, trata-se de um olhar (atenção) que não se fixa em demasia, esquecendo-se do que acontece à sua volta, nem relaxa (abre-se) em demasia, perdendo-se nos próprios acontecimentos ou ignorando-o; traduzindo-se numa experiência de lucidez precedida por um abandono temporário de um lastro teórico que conforma nosso olhar a esquemas já estruturados. Neste sentido, uma experiência de suspensão dos julgamentos racionais e de um descentramento da atenção voltada para o eu em favor do que acontece ou de quem o interpela (fora do pensamento). A imagem do esvaziamento é bastante ilustrativa deste processo, sinteticamente, esvaziar para receber. (ESQUIROL, 2008)

Acentuando o caráter ético da atenção, Pierre Hadot $(1999,2003,2009)$ formulou uma concepção de filosofia como modo de viver, sustentado sobre a prática de exercícios espirituais que têm como finalidade uma formação humana que decorre de uma autoformação (autotransformação). A atenção (prosokhé) constituía um dos exercícios espirituais praticado nas escolas filosóficas de Epicuro e de Sêneca. Grosso modo, definido como um esforço para tornar-se presente no momento vivido, um estado de abertura que comporta um abandono completo e total da vinculação do presente vivido tanto do passado, quanto do futuro, para dar-se conta da maravilha do presente, sempre novo.

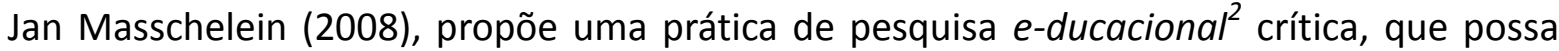
nos inscrever corporalmente num movimento que visa examinar, no sentido de prestar atenção e que implica em uma atitude. Para ele, a e-ducação do olhar visa à libertação de nosso olhar de qualquer perspectiva predeterminada, com o objetivo de torná-lo atento.

Esquematicamente, podemos dizer que e-ducar o olhar requer primeiramente uma prática de pesquisa crítica, que realize uma mudança prática em nós e no presente em que vivemos (e não

\footnotetext{
${ }^{2}$ Explica o autor que o termo e-ducação (com hífen) vincula-se com a palavra latina educere, compreendido como trazer para fora, indicar, apresentar, contrastando com educare, no sentido de ensinar, transmitir. 
uma fuga para um pretenso futuro melhor). Prática que não depende de método, mas sim de disciplina. Que não requer uma metodologia rica, mas exige uma pedagogia pobre. Ou seja, práticas que permitam a ex-posição (de) nossa condição de sujeito, no sentido de estar "fora de posição", indicando um movimento, que nos leve à rua e que nos desloque corporalmente. Para Masschelein (2008), e-ducar o olhar pode ser pensado como um convite para caminhar:

A força de uma estrada do campo é diferente quando caminhamos por ela e quando voamos sobre ela num avião. Da mesma forma, a força de um texto quando lido é diferente de sua força quando copiado. Quem voa vê apenas o modo como a estrada penetra pela paisagem, como ela se desdobra de acordo com as leis da paisagem ao seu redor. Somente quem anda a pé pela estrada conhece a força que ela tem, e como, da mesma paisagem que para quem voa é apenas uma planície aberta, ela desvenda distâncias, mirantes, clareiras, panoramas a cada curva como um comandante posicionando soldados numa frente de batalha. É somente o texto copiado que comanda, assim, a alma de quem se ocupa dele, ao passo que o mero leitor jamais chega a descobrir os novos aspectos de seu interior que são abertos pelo texto, a estrada corta ao meio a floresta que vai constantemente se fechando atrás dela: porque o leitor segue o movimento de sua mente no vôo livre da imaginação, enquanto quem copia submete a mente ao seu comando. (BENJAMIM, 2013, p. 14).

Na interpretação de Masschelein (2008), caminhar e copiar são práticas de uma pesquisa educacional crítica diferentes das atividades de voar e ler, circunscritas à noção de representação de base moderna, cujo posicionamento do sujeito do conhecimento, munido de um método proporciona a verdade. Caminhar por dentro da estrada é diferente da experiência de voar sobre ela porque quem caminha por dentro da estrada deve ser obediente à evidência da manifestação de sua força, que comanda através das clareiras, nas encostas, nos vales, mas quem voa, vê apenas (tem uma representação/perspectiva), não é comandando pela força da estrada.

Visão além de toda perspectiva e olhar que nos transforma é, portanto, experiência que implica um descentramento do eu (sujeito do conhecimento), já que toda perspectiva está presa à posição do sujeito em relação a um objeto/objetivo e caminhar significa colocar essa posição em jogo, significa ex-posição, estar fora de posição, em que a alma se dissolve a partir do interior, a partir da ex-posição do sujeito.

Caminhar pela estrada faz com que a estrada se imponha sobre nós com certa autoridade, para que ela conduza o nosso olhar e nos apresente uma realidade dramática, que nos co-mova (que nos ponha em movimento) em suas diferenças. Não se trata, portanto, de chegar a uma determinada perspectiva mas de uma relação totalmente diferente com o presente; relação de movimento que não se conforma ou confirma, mas que atravessa as intenções e interesses que posicionam/identificam o sujeito/objeto.

Caminhar pela estrada é uma maneira de explorar e relacionar-se com o presente e constitui um tipo de prática de pesquisa que envolve estar atento, constitui um modo diferente de relacionar-se com o mundo, relacionar-se com o presente, com o que está presente. Trata-se, na verdade, de uma diferença de força, do efeito que aquela atividade tem sobre nós mesmos e sobre o que é revelado, pois, quem voa, vê apenas, mas quem caminha pela estrada aprende com a sua força, vivencia a trilha como algo que se oferece/aparece, que se apresenta, torna-se evidente e comanda a alma.

Nas abordagens sintetizadas acima (ESQUIROL, 2008; MASSCHELEIN, 2008; HADOT, 1999, 2003, 2009), a atenção cumpriria um importante papel na formação humana através de um esforço que culminaria na autoformação. Embora tratem a temática de maneira variada, um 
primeiro ponto importante a ser destacado para o qual convergem tais abordagens é a valorização dos elementos da sensibilidade, dentro da qual se inclui a corporalidade e a materialidade do mundo na produção de sentido e de presença.

A experiência do Caminhar revela-se como uma prática que envolve ver, abrir os olhos, ter um novo olhar e prestar atenção, ao mesmo tempo livre de perspectivas ou visões; que exige um deslocamento, uma mudança que permita que nós estejamos aqui (lá) e para que o lá (aqui) se apresente a nós em sua evidência.

Embora, Masschelein (2008) faça referência a um tipo de exercício que requer o movimento do corpo, podemos pensar, no caso da formação filosófica, no movimento (caminhada) do pensamento quando este se torna uma experiência de pensamento filosófica. Para ilustrar este esforço concreto, de maneira esquemática, destacamos três autores que narram suas experiências em que o movimento (do corpo) exaurindo suas energias de projeção e de apropriação através de uma disciplina do corpo e da mente, colocaram-se no lugar do vulnerável: Henry David Thoreau (2012), Frédéric Gros (2014) e David Le Breton (2015).

Em uma perspectiva literária, Henry David Thoreau (2012) em Andar a pé apresenta uma meditação acerca do seu hábito de caminhar pelas florestas na América do Norte do século XIX. Suas narrativas revelam um processo de (auto)formação em que se combina a atividade corporal (caminhar) com a atenção, no sentido conferido por Masschelein (2008). Não se trata da caminhada como exercício de desenvolvimento corporal, associado contemporaneamente a noção de performance. Mas como diz Thoreau (2003, p. 9), trata-se do motivo e da aventura do dia. Sobretudo, continua ele, devemos "[...] caminhar como um camelo o qual, ao que sabemos, é o único animal capaz de ruminar em marcha." (THOREAU, 2012 p. 9)

Sob enfoque sociológico e visando o resgate da corporalidade, David Le Breton (2015) em Elogio del caminar nos diz que um caminhar realizado com prazer e com coração, como convite ao encontro, a conversação e ao desfrute do tempo, pode tornar-se uma abertura para o mundo, restituindo ao homem um feliz sentimento de sua existência. Configurando como uma meditação ativa que requer uma sensorialidade plena (p.15) e que tem o potencial de nos transformar face às demandas contemporâneas de tempo e lucro, pois: "Recurrir al bosque, a las rutas o a los senderos, (...) nos permite recobrar el aliento, aguzar los sentidos, renovar la curiosidad. El caminar es a menudo un rodeo para reencontrarse con uno mismo." (LE BRETON, 2015, p.15. Itálico nosso).

Neste sentido, caminhar no contexto contemporâneo pode servir como resistência política e como triunfo do corpo que proporciona uma filosofia elementar da existência "(...) basada en una serie de pequeñas cosas; conduce durante un instante a que el viajero se interrogue acerca de sí mismo, acerca de su relación con la naturaleza o con los otros, a que medite, también, sobre un buen número de cuestiones inesperadas." (LE BRETON, 2015, p. 18-19).

Para Frédéric Gros (2010), em Caminhar, uma filosofia apresenta a ideia de que a caminhada é também um ato filosófico e uma experiência espiritual. Entre seus interlocutores filosóficos estão Nietzsche, Rimbaud, Rousseau, Thoreau e Kant. Embora não se enquadre como um tratado filosófico sobre a caminhada, suas reflexões abordam os temas existenciais presentes no espírito humano que não descansam até podermos tratá-los (pensá-los/percorrê-los), mostrando também, de maneira poética, que importantes insights filosóficos nasceram durante longas caminhadas e perambulações.

\section{DISCUSSÃO}

Para Esquirol (2008) a atenção revela-se como uma espécie de desapego em relação a si mesmo, uma suspensão do pensamento para deixá-lo mais disponível e penetrável. Para Jan Masschelein (2008) a relação da atenção com o sujeito implicaria também sua suspensão na medida em que a atenção deslocaria o sujeito em relação ao objeto, a ponto de colocar em risco sua própria constituição (de sujeito). Tal perspectiva, aberta particularmente por Masschelein 
(2008), constitui-se problemática na medida em que nos apresenta a tarefa de pensar nas fronteiras do regime de verdade de corte moderno/representacional, em que a noção de formação está associada à constituição do sujeito uno, singular, portador de identidade, racional, autônomo e livre; artífice de um mundo e de uma realidade constituída de objetos passíveis de serem conhecidos e controlados pelo sujeito do conhecimento. ${ }^{3}$

Para Masschelein (2008), estar atento é não se deixar cativar (aprisionar) por nenhuma intenção, ou projeto, ou visão, ou perspectiva, ou imaginação, que sempre nos dão um objeto e capturam o presente numa representação. Estar atento requer a suspensão do tribunal da razão e implica um tipo de espera, tendo por finalidade cortar a realidade para que possamos ver o ponto cego contido naquilo que é evidente (MASSCHELEIN, 2008). Neste sentido, prestar atenção indicaria uma atitude de estar presente ao presente, de tal forma que ele seja capaz de se apresentar para que possamos ser transformados, atravessados ou contaminados por ele, tornando a experiência possível.

\section{CONCLUSÃO}

A atenção em seu registro ético-existencial desloca a soberania do sujeito em relação ao seu objeto, colocando em risco sua própria constituição. Neste descentramento, surge um espaço de liberdade prática, tornando possível a transformação tanto do sujeito quanto do objeto. Neste sentido, trata-se de um modo de atenção que prescinde de intenção, muito embora, permaneça um certo tensionamento, manifesto como uma abertura e uma estado desperto (foco) ao que acontece.

Trata-se de uma atitude geral, com contornos ético-existenciais, que possibilita a ex-posição e a vulnerabilidade. Ex-posição que significa a saída de uma posição determinada e caminhar, por meio de um movimento que transforma o foco atentivo a cada passo dado, possibilitando a visão dos vales, encostas e planícies e que transforma também o sujeito (da experiência), que vulnerável aos contornos do próprio caminho, é comandando por sua força.

Partindo de uma concepção de filosofia desviante dos pressupostos representacionais, presa do discurso epistemológico, queremos considerar uma formação filosófica não restrita ao acúmulo de erudição mas dependente de uma certa experiência de pensamento que se faz, dependente de um certo caminho que se percorre, no qual seja possível a ex-posição na condição do vulnerável.

Formação filosófica pensada desde os riscos de um caminhar sem mapas e sem rotas previamente estabelecidas, dentre os riscos a que o caminhante está sujeito quando caminha pela estrada, sem mapas e sem roteiros previamente estabelecidos, a errância é um dos mais comuns. Neste sentido, embora haja um imperativo em caminhar, o caminhante não dispõe dos mapas e não sabe qual caminho tomar, restando-lhe a alternativa de errar.

É nesse processo do se perder para melhor se encontrar ou melhor da errância, que o caminhante, atento as indicações do caminho, descentrados em relação aos domínios (pois lhe faltam) próprios do sujeito do conhecimento, permanece aberto e livre, ao menos por um tempo, do peso de um lastro teórico (representações) que existe enquanto marcador da realidade, conformando a experiência possível às suas determinações e impedindo assim o surgimento do novo e do encontro com a maravilha do fora do pensamento.

\footnotetext{
${ }^{3}$ Danelon (2003), em sua tese de doutorado, procurou demonstrar que a educação, de modo geral, repousa sobre a premissa da existência de um sujeito a ser formado/formatado e as disciplinas que compõem as ciências da educação, seja a psicologia da educação, a sociologia da educação, as metodologias, entre outras, estão baseadas na idéia desse mesmo sujeito a ser educado: sujeito uno, singular, sede da razão, liberdade, vontade e consciência. Concepção que fundamenta práticas, currículos e a legislação educacional.
} 


\section{REFERÊNCIAS}

ABBAGNANO, N. Dicionário de Filosofia. Trad. Alfredo Bosi. São Paulo: Martins Fontes, 2003.

BENJAMIM, W. Rua de mão única. Trad. Ed. João Barrento. São Paulo: Autêntica, 2013.

Passagens. Trad. Irene Aron e Cleonice Paes Barreto Mourão. Belo Horizonte/São

Paulo: Editora UFMG/Imprensa Oficial do Estado de São Paulo, 2007.

ESQUIROL, J.-M. O respeito ou o Olhar atento: Uma ética para a era da ciência e da tecnologia. Belo Horizonte: Autêntica, 2008.

GROS, F. Caminhar, uma filosofia. Ed. É Realizações, 2010.

HADOT, P. O que é filosofia antiga? São Paulo: Loyola, 1999.

Exercices Spirituels et philosophie antique. Paris: Albin Michel S.A, 2003.

La filosofía como forma de vida: Conversaciones com Jeannie Carlier Y Arnold Davidson. Barcelona: Alpha Decay, 2009.

LE BRETON, D. Elogio del caminar. Vol. 58. Siruela, 2015.

LEOPOLDO E SILVA, F. Descartes: A Metafísica da modernidade. Ed. Moderna, 2001.

MASSCHELEIN, J. E-ducando o olhar: a necessidade de uma pedagogia pobre. Educação \& Realidade. p. 35-48, 33(1), jan/jun, 2008.

SANTOS, G.S. A importância da atenção na relação professor-aluno no contexto tecnocientífico. 2012. 199 f. Tese (Doutorado em Educação) - Faculdade de Filosofia e Ciência, Marília, 2012.

THOREAU, H.D. Andar a pé. Montecristo Publishing LLC, 2012. 